\title{
Production of Natural Coagulant from Moringa Oleifera Seed for Application in Treatment of Low Turbidity Water
}

\author{
Eman N. Ali", Suleyman A. Muyibi, Hamzah M. Salleh, \\ Md Zahangir Alam, Mohd Ramlan M. Salleh \\ Biotechnology Engineering Department, Faculty of Engineering, \\ International Islamic University Malaysia, Kuala Lumpur, Malaysia \\ E-mail:iman129@yahoo.com \\ Received September 29, 2009; revised October 7, 2009; accepted October 19, 2009
}

\begin{abstract}
This study focused on developing an efficient and cost effective processing technique for Moringa oleifera seeds to produce natural coagulant for use in drinking water treatment. The produced natural coagulant can be used as an alternative to aluminum sulphate and other coagulants and used worldwide for water treatment. This study investigates processing Moringa oleifera seeds to concentrate the bio-active constituents which have coagulation activity. Moringa oleifera seeds were processed for oil extraction using electro thermal soxhlet. Isolation and purification of bio-active constituents using chromatography technique were used to determine the molecular weight of the bio-active constituents. The molecular weight of bio-active constituents found to be in a low molecular weight range of between $1000-6500$ Dalton. The proposed method to isolate and purify the bio-active constituents was the cross flow filtration method, which produced the natural coagulant with very simple technique (oil extraction; salt extraction; and microfiltration through $0.45 \mu \mathrm{m}$ ). The turbidity removal was up to $96.23 \%$ using $0.4 \mathrm{mg} / \mathrm{L}$ of processed Moringa oleifera seeds to treat low initial turbidity river water between 34-36 Nephelometric Turbidity Units (NTU) without any additives. The microfiltration method is considered to be a practical method which needs no chemicals to be added compared to other researchers proposed methods. The natural coagulant produced was used with low dosages to get high turbidity removal which considered to be a breakthrough in this study and recommended to be scaled up for industry level. The product is commercially valuable at the same time it is minimizing the cost of water treatment.
\end{abstract}

Keywords: Moringa Oleifera, Drinking Water Treatment, Bioactive Constituents, Coagulation, Flocculation, Turbidity

\section{Introduction}

Developing countries are facing potable water supply problems because of inadequate financial resources. The cost of water treatment is increasing and the quality of river water is not stable due to a suspended and colloidal particle load caused by land development and high storm runoff during rainy season, such is experienced in a country like Malaysia.

About 1.2 billion people still lack safe drinking water and more than 6 million children die from diarrhea in developing countries every year. In many parts of the world, river water that can be highly turbid is used for drinking purposes. World Health Organization (WHO) has set the guideline value for the residual turbidity in drinking water at 5 Nephelometric Turbidity Units (NTU) [1]. As identified by the United States Environmental Protection Agency (USEPA), turbidity is a measure of the cloudiness of water; it is used to indicate water quality and filtration effectiveness. Higher turbidity levels are often associated with higher levels of disease-causing micro organisms such as viruses, parasites and some bacteria. These organisms can cause symptoms such as nausea, cramps, diarrhea, and associated headaches [2].

Water-borne infectious disease caused by viruses, bacteria, protozoa and other micro organisms is associated 
with outbreaks of and background rates of disease in developed and developing countries worldwide [3].

Naturally occurring coagulants are usually presumed safe for human health. Earlier studies have found the Moringa oleifera seeds are non-toxic, and recommended its use as coagulant in water treatment in developing countries.

Moringa oleifera is the best natural coagulant discovered so far that can replace aluminum sulphate (alum), which is used widely for water treatment around the world.

The consumption of alum is very high in water treatment in Malaysia. The main concern in this study is low turbidity water which was difficult to be treated according to other researcher's presentations. The ideal plant for low turbidity water treatment in Malaysia is Wangsa Maju Water Treatment Plant (Puncak Niaga (M) Sdn Bhd) which was used for comparison in this study, the process flow sheet (Appendix A). The plant is working to treat the low turbid water with initial turbidity of 30 NTU or less. The process depends on using several additives to get residual turbidity of less that 5 NTU. The dose of alum usually used is between $13-18 \mathrm{mg} / \mathrm{L}$, chlorine is added with an amount of $3.55 \mathrm{Kg} / \mathrm{hour}$, and for post chlorination $5.5 \mathrm{Kg}$ /hour, besides adding fluoride 0.5-0.6 mg/L, lime $\left(\mathrm{CaCO}_{3}\right)$ for $\mathrm{pH}$ adjustment, and Chamfloc 151 sludge dewatering with an amount of $3 \%$ $\mathrm{w} / \mathrm{w}$. Some chemicals are local and some are imported (Personal communications). Therefore, this study focused on the treatment of low turbidity water.

\section{Materials and Methods}

The proposed method to isolate and purify the bio-active constituents is the cross flow filtration method, which produced the natural coagulant with very simple technique (oil extraction; salt extraction; and microfiltration through $0.45 \mu \mathrm{m})$. Process flow chart is shown in Figure 1.

\subsection{Preparation of Moringa oleifera seeds}

Good quality dry seeds of Moringa oleifera were selected from the pods that were collected from Serdang, Selangor Darul Ehsan, Malaysia. The pods collected were allowed to completely dry on the tree (the brown colour pods) because the green pods do not possess any coagulation activity [4].

The pods length ranged between $(40-60) \mathrm{cm}$, and each pod contained around (20-30) seeds. The seeds coat and wings were removed manually, followed by the grinding of the seeds into a fine powder using a domestic blender (National, MX-896TM), then sieving the ground powder through $250 \mu \mathrm{m}$ sieve (Figure 2).

\subsection{Oil Extraction}

Prior to extraction of bioactive constituents through ion exchange resin, the ground and sieved Moringa oleifera seed powder with size of $<250 \mu \mathrm{m}$ was defatted with hexane by using electro thermal soxhlet apparatus (ROSS, UK). This was done by weighing of $10 \mathrm{gm}$ of Moringa oleifera seed powder and setting it in the thimbles of the electro thermal soxhlet extraction chamber, adding $170 \mathrm{ml}$ of hexane in the heating chamber, then evaporating of hexane through three cycles each for 30 min to ensure the extraction of oil from the seeds, until the hexane became colorless, drying of Moringa oleifera cake residue from the soxhlet thimbles and weighing the dry sample [5].

The Moringa oleifera cake residue stock after oil extraction was used in this study; the oil percentage was 35 $\% \mathrm{w} / \mathrm{w}$. The sample of $1 \mathrm{Kg}$ was defatted and kept to be used throughout the study period at room temperature a round $23 \pm 2{ }^{\circ} \mathrm{C}$.

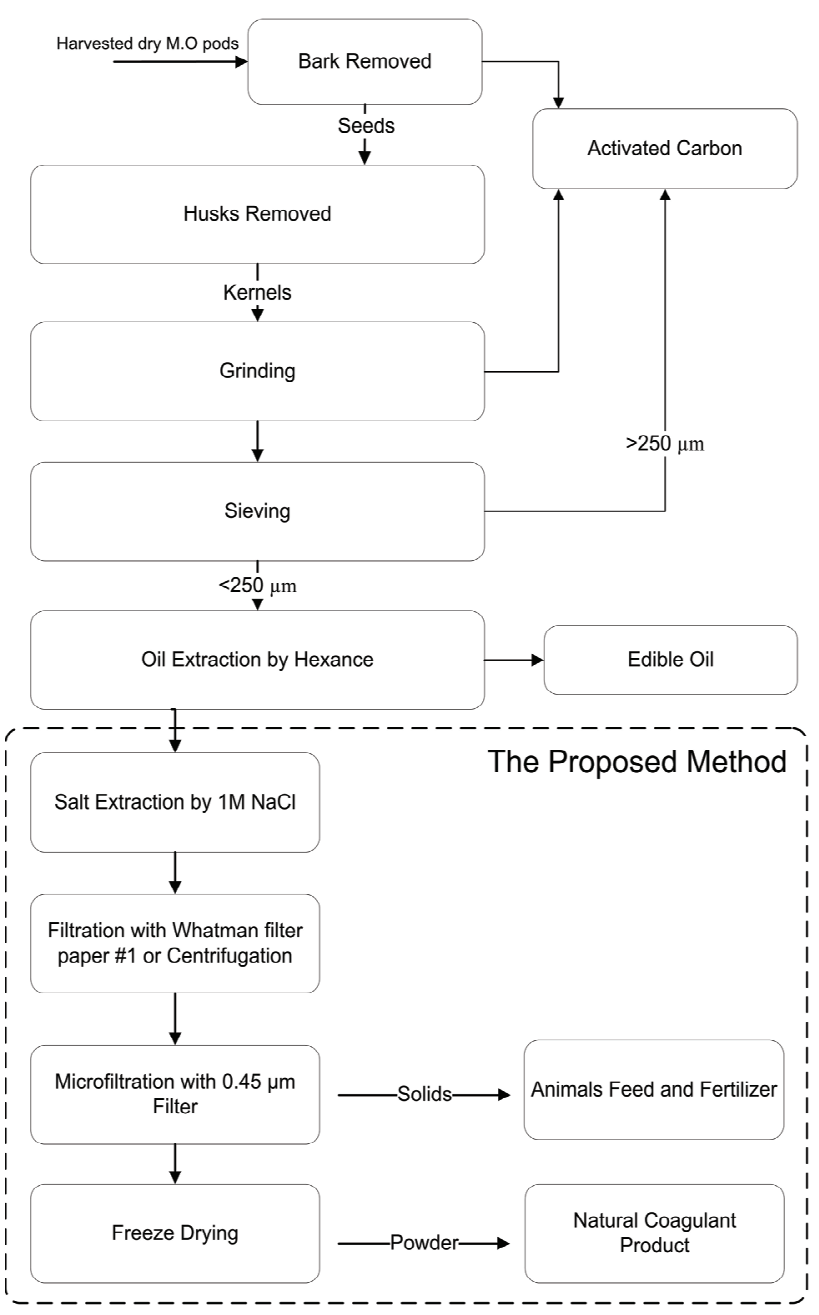

Figure 1. Proposed production process flow chart. 

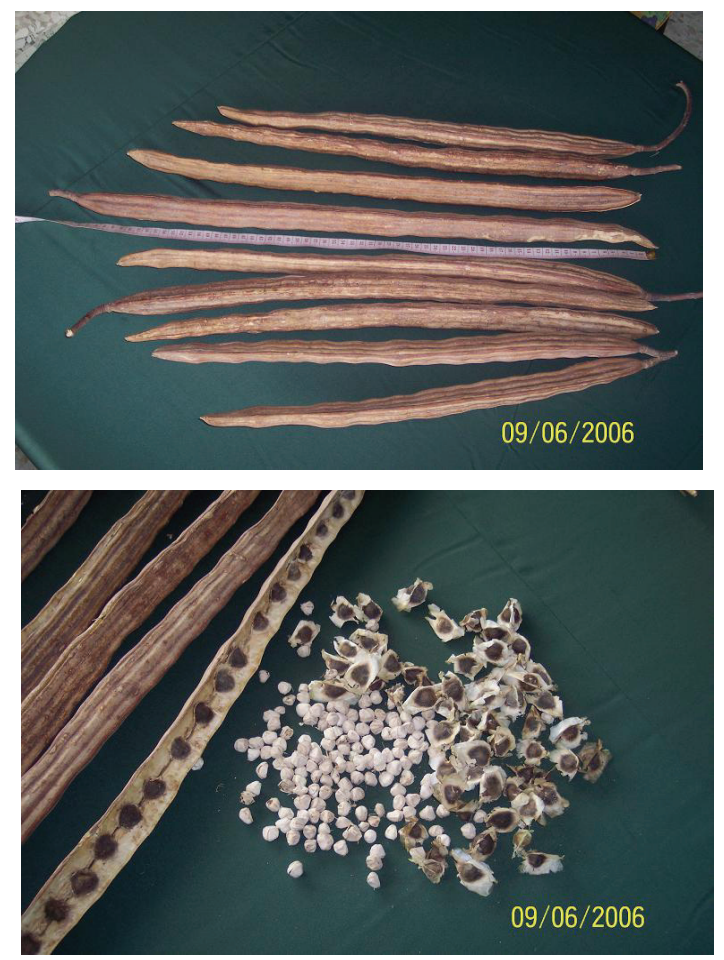

Figure 2. Moringa oleifera pods and seeds.

\subsection{Salt Extraction}

The extraction was done by adding a sloution of 1 Molar $\mathrm{NaCl}$ to the sample and mixed for 30 minutes using the magnetic stirrer (ERLA, ERLA Technologies (M) Sdn. Bhd. Malaysia). The extracted solution was centrifuged at $6000 \mathrm{rpm}$ for a period of 10 minutes using the centrifuge (Eppendorf, 5804R, Germany). The supernatant was injected to ion exchange column.

\subsection{Ion Exchange Process}

The ion exchange technique was followed to isolate and purify the bioactive constituents for molecular weight measurements. The steps of the process were as follows:

\subsubsection{Buffers Preparation}

Two buffers were prepared for this stage of research as follows:

- Phosphate buffer stock (1 M): Phosphate buffer stock $(1 \mathrm{M})$ with $\mathrm{pH} 7.5$ was made by adding $174.16 \mathrm{gm}$ of di-potassium hydrated phosphate $\left(\mathrm{K}_{2} \mathrm{HPO}_{4}, \mathrm{GmBH}\right.$ Chemicals, Germany) into $900 \mathrm{ml}$ of distilled water. The $\mathrm{pH}$ of the solution was 9.41 which were adjusted to 7.5 by adding $5 \mathrm{M} \mathrm{HCl}$. The preparation of the buffer stock solution was finalized by adjusting the volume to 1000 $\mathrm{ml}$ by adding distilled water.

- Buffer A (0.1 M phosphate buffer): Preparation of $0.1 \mathrm{M}$ phosphate buffer was by adding $100 \mathrm{ml}$ of $1 \mathrm{M}$ phosphate buffer stock into $900 \mathrm{ml}$ of distilled water, $0.02 \% \mathrm{NaN}_{3}$ was added to the solution as anti-bacterial agent.

- Buffer B (1.0 M NaCl in $0.1 \mathrm{M}$ phosphate buffer): This buffer was prepared by adding $58.44 \mathrm{gm}$ of $\mathrm{NaCl}$ (GmBH Chemicals, Germany) to $900 \mathrm{ml}$ of buffer A, and adjusting the volume to $1000 \mathrm{ml}$.

\subsubsection{Preparation of the Column}

The Glass Column $(300 \times 25 \mathrm{~mm}$, with Bio-Rex Resin 70 , Bio-Rad, USA) was used for ion exchange. The resin (Bio-Rex 70) was prepared by adding the resin powder to buffer A, and mixing the contents until the slurry was homogenous. Afterwards, the slurry was loaded to the glass column. The resin was then washed with $2 \mathrm{M} \mathrm{NaCl}$ to remove any impurities that may be present in the resin. It was then washed with buffer A to equilibrate the column to be ready for the loading of the sample.

2.4.3. Loading of the Sample to Ion Exchange Column Equilibrate the column with $300 \mathrm{ml}$ of $0.1 \mathrm{M}$ phosphate buffer. Loading $30 \mathrm{ml}$ of the extracted proteins sample as prepared in 2.3 above. Applying buffer A with an amount equal to twice of the column volume $(300 \mathrm{ml})$ to wash all the unwanted negative charged proteins. Applying buffer $\mathrm{B}$ with $1 \mathrm{M} \mathrm{NaCl}$, and buffer (A and $\mathrm{B}$ ) and mixing them before sending to ion exchange. The flow rate was adjusted at $2 \mathrm{ml} / \mathrm{min}$, and the fractions collected were 120 fractions with $5 \mathrm{ml}$ volume each. Measuring absorbance of fractions using spectrophotometer (SECOMAM, Anthelie Advanced, France) at wave length 280 $\mathrm{nm}$. The absorbance for the eluted fractions is plotted and 11 points were chosen for molecular weight measurements as shown in Figure 3.

\subsection{Determination of Molecular Weight}

High performance liquid chromatography (HPLC) equipment was used. The bio-active constituents purified by chromatography technique were injected to HPLC to determine the molecular weight. Eleven points were

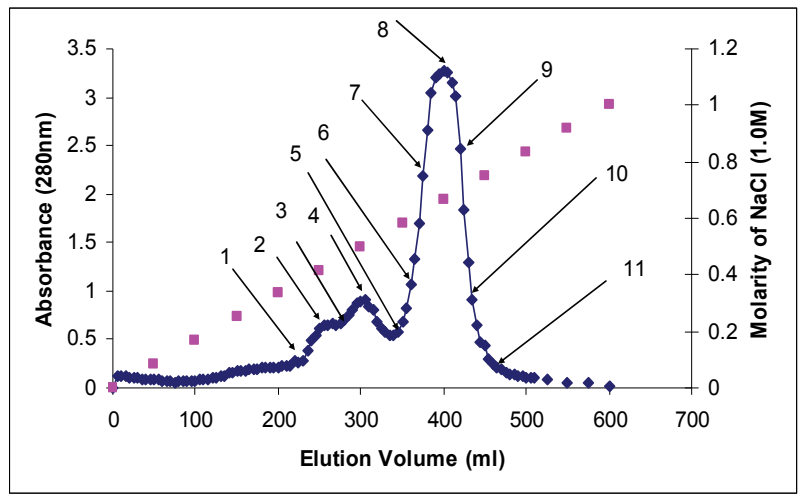

Figure 3. Eluted fraction from Ion exchange column. 
selected from Figure 3 to measure the molecular weight of different eluted fractions. HPLC (Waters 1525 with Binary HPLC Pump, Waters 2487 Dual $\lambda$ Absorbance Detector, and Breeze GPC software, from Waters, 34 Maple Street Milford, MA 01757, USA) was used to measure the molecular weight of the bioactive constituents with Gel Filtration Column $300 \times 7.8 \mathrm{~mm}$ (Bio-Sil SEC-125) for molecular weight measurement besides guard column $80 \times 7.8 \mathrm{~mm}$ (Bio-Sil 125)was connected before the column to the HPLC to protect the column. The standard used was Bio-Rad Gel Filtration Standard with Thyroglobulin, IgG, Ovalbumin, Myoglobin, and Vitamin B12. The molecular weight is $670,158,44,17$, and $1.35 \mathrm{kDa}$, respectively. The buffer used was sodium phosphate (GmBH Chemicals, Germany). Filter paper (Waters GHP $0.45 \mu \mathrm{m}$ ) was used to filter the sample before injecting into HPLC.

The buffer used for HPLC was prepared as follows: $0.5 \mathrm{M} \mathrm{NaH}_{2} \mathrm{PO}_{4} ; 0.5 \mathrm{M} \mathrm{Na}_{2} \mathrm{HPO}_{4}$ : $1.5 \mathrm{M} \mathrm{NaCl}$; and 0.10 $\mathrm{M} \mathrm{NaN}$. The buffer used as a mobile phase for the HPLC is mixture from the above solutions as follows: $100 \mathrm{ml}$ of $0.5 \mathrm{M} \mathrm{NaH}_{2} \mathrm{PO}_{4}, 100 \mathrm{ml}$ of $0.5 \mathrm{M} \mathrm{Na}_{2} \mathrm{HPO}_{4}$, $100 \mathrm{ml}$ of $1.5 \mathrm{M} \mathrm{NaCl}, 100 \mathrm{ml}$ of $0.10 \mathrm{M} \mathrm{NaN}_{3}$. Subsequently by adding the above solution to one litre flask and completing the volume to $1000 \mathrm{ml}$ by adding distilled water. The buffer prepared is contained the following concentration: $0.05 \mathrm{M} \mathrm{NaH} \mathrm{PO}_{4}, 0.05 \mathrm{M}$ $\mathrm{Na}_{2} \mathrm{HPO}_{4}, 0.15 \mathrm{M} \mathrm{NaCl}, 0.01 \mathrm{M} \mathrm{NaN}_{3}$ with $\mathrm{pH}=6.8$, and this Eluant is used as mobile phase in HPLC.

\subsection{Cross Flow Filtration}

The proposed method of microfiltration and ultrafiltration were performed for bioactive constituent's separation. The microfiltration followed by ultrafiltration was carried out as follows:

\subsubsection{Microfiltration}

The use of microfiltration was to reduce the organic load in the processed Moringa oleifera seeds. Cross flow filtration (QuixStand Benchtop System, Sweden), with peristaltic pump (Watson-Marlow Bredel Pumps, Falmonth Cornwall TR 11 4RU, England) was used. The microfiltration cartridge (CFP-4-E-3MA) were used for sample filtration with pore size of $0.45 \mu \mathrm{m}$ with a fiber ID $1 \mathrm{~mm}$, membrane area $110 \mathrm{~cm}^{2}$, and nominal flow path length $30 \mathrm{~cm}$. The structure is a polysulfone membrane which operates in a vertical orientation complete process fluid drainage. It is typical for concentration and purification of proteins, and suitable for scaling-up studies (GE Healthcare Bio-Science Corp. USA). The supernatant was then injected to ultrafiltration cartridge.

The new cartridge needs to be washed although it is shipped dry. It was washed with warm distilled water (55 $\left.{ }^{\circ} \mathrm{C}\right)$ and rinsed for 5 minutes at a pressure of 0.3 bar $(5$ psig).

\subsubsection{Ultrafiltration Process}

The Xampler ultrafiltration cartridge (UFP-1-C-3M) was used for bioactive constituents separation with cutoff of 1000 Dalton, with fibre ID $0.5 \mathrm{~mm}$, membrane area 140 $\mathrm{cm}^{2}$, and nominal flow path length $30 \mathrm{~cm}$, the type of membrane is polysulfone hollow fibre type (GE Healthcare Bio-Science Corp. USA).

\subsection{Coagulation Activity Tests}

The jar test was performed to monitor the coagulation activity of the processed Moringa oleifera seed in water treatment.

\subsubsection{Synthetic Water (Kaoline Suspension) Preparation} A weight of 5 gm of Kaoline, laboratory grade (K7375, particle size 0.1-4 $\mu \mathrm{m}$, Sigma-Aldrich), was dissolved with $500 \mathrm{ml}$ of distilled water. Sodium bicarbonate solution with concentration of $100 \mathrm{mg} / \mathrm{l}$ was prepared by adding $100 \mathrm{mg}$ of sodium bicarbonate (GmBH Chemicals, Germany) to $1000 \mathrm{ml}$ of distilled water; Adding 500 $\mathrm{ml}$ of the sodium bicarbonate solution to the kaoline; Stirring the mixture at $200 \mathrm{rpm}$ for 60 minutes to uniform the dispersion of clay particles. The suspension then was allowed to stand for 24 hours for complete hydration of the kaoline $[4,6,7]$. This is the stock kaoline solution for the coagulation activity evaluation throughout the study period and this stock was diluted a few times to get the turbidity needed for each particular test.

\subsubsection{Jar Test}

The jar test was performed for each stage of purification process to monitor the coagulation activity. The method applied was according to [5] with rapid mixing of 125 rpm for 4 minutes, followed by slow mixing of $40 \mathrm{rpm}$ for 25 minutes and settling time of 1 hour. The jar test was carried out using (Stuart Flocculator SW6, Barloworld, UK) equipped with six paddles rotating in a set of six beakers. A turbidimeter 2100P (HACH company, USA) was used for all turbidity measurements.

\section{Results and Discussion}

The molecular weight of the chosen eleven points for this study showed different low range molecualr weight (Table 1). All the points have low molecular weight which is ranged from 6500 to less than 1350 Dalton. The eluted fractions from the ion exchange column were used to monitor the coagulation activity and measuring the turbidity removal using the conventional jar test method. The results of turbidity removal percentage are tabulated in Table 2. 
Table 1. Molecular weight for 11 points selected in Figure 3.

\begin{tabular}{ccc}
\hline Point \# & Retention time (min) & Molecular weight Range (Dalton) \\
\hline 1 & 11.40 & $\sim 4000$ \\
2 & $11.20,11.50,12.20$ & $\sim 5000, \sim 3500,<1350$ \\
3 & $11.20,11.40$ & $\sim 5000, \sim 4000$ \\
4 & $11.10,11.40$ & $\sim 6000, \sim 4000$ \\
5 & $11.50,13.20$ & $\sim 3500,<1350$ \\
6 & $11.387,12.167,13.070$ & $\sim 4000,<1350$ \\
7 & $11.10,11.50,12.20,13.00$ & $\sim 6000, \sim 3500,<1350$ \\
8 & $11.00,11.40,12.00$ & $\sim 6500, \sim 4000,1500$ \\
9 & $11.50,12.30,13.05$ & $\sim 3500,<1350$ \\
10 & $11.374,12.162,13.016$ & $\sim 4000,<1350$ \\
11 & $11.383,12.107,13.110$ & $\sim 4000,<1350$ \\
\hline
\end{tabular}

Table 2. Turbidity removal percentage for 11 selected points.

\begin{tabular}{ccc}
\hline Sample \# & Optimum residual turbidity (NTU) & Turbidity removal \% \\
\hline 1 & 10.62 & 64.60 \\
2 & 2.23 & 92.13 \\
3 & 2.95 & 90.16 \\
4 & 1.78 & 94.08 \\
5 & 2.03 & 93.24 \\
6 & 1.38 & 95.39 \\
7 & 5.21 & 82.63 \\
8 & 4.71 & 84.29 \\
10 & 1.65 & 94.49 \\
11 & 0.64 & 97.12 \\
\end{tabular}

The main concern in using Moringa oleifera for water treatment is the significant increase in organic load, as organic matters originating from the seeds can be released into the water during treatment $[8,9]$. The presence of organic matter in treated water can cause problems of colour, taste, and odour, and also facilitates the development of microorganisms upon storage [10]. Jahn [11] reported that water treated with crude Moringa oleifera extract should not be stored for more than 24 hours. The crude extract is therefore not generally suitable for large water supply systems where the hydraulic residence time is very high. Oil extraction is of a great advantage here, to reduce the organic load from the seeds, and to produce edible oil as a by-product. It is clearly possible to extract oil first and then use the aqueous extract as a coagulant. This dual exploitation is even advantageous for isolation and purifying the active agents in the coagulation with Moringa oleifera seed and also for the reduction of organic matter concentration in the treated water [4].

Two steps were followed to produce the natural coagulant by cross flow filtration. The first step was microfiltration, which is important for reducing the organic matters concentration. The main concern here is to filter all the oil from the seeds to reduce the organic content, because it can act as a precursor of trihalomethane formation during the disinfection process by chlorine which may be carcinogenic [8]. It is also may be postulated that the oil content in the seed will form an emulsion or film coating which may inhibit the contact with the surface of reaction and thus reduce floc formation. Extraction of the oil may therefore enhance the turbidity removal, resulting in better coagulation and flocculation [12].

The second step was ultrafiltration with 1000 Dalton cutoff membrane. In this study a simple scalable purification method was found. This is a straightforward production method of processed Moringa oleifera for water treatment.

The sample of Moringa oleifera seeds was processed as mentioned in Subsections 2.1, 2.2, and 2.3. The extract from the salt extraction process was filtered with Whatman filter paper \#1 to remove all the solids from the extract. It was then applied for microfiltration with $0.45 \mu \mathrm{m}$ microfiltration cartridge. Ndabigengesere \& Narasiah [8] used $0.45 \mu \mathrm{m}$ for microfiltration but the extraction method was with water, followed by many complicated steps to produce the coagulant, and the chemical oxygen demand increased by increasing the dose. No other research has been done on the microfiltration process. Permeate collected from microfiltration process was applied in the QuixStand Benchtop System apparatus to separate the retentate and permeate according to the molecular weight cutoff of 1000 Dalton.

The jar test was performed by using synthetic water and applying the three samples produced from: 1$)$ microfiltration $(0.45 \mu \mathrm{m}), 2)$ the retentate of ultrafiltration (1000 Dalton), and 3) permeate of ultrafiltration (1000 Dalton), and the results of residual turbidity are shown in 
Figures 4, 5, and 6, respectively.

From the results obtained, $0.45 \mu \mathrm{m}$ microfiltration, showed a low residual turbidity of 1.32 NTU by adding $0.4 \mathrm{mg} / \mathrm{L}$ of processed Moringa oleifera to the synthetic water samples (Figure 4) with turbidity removal of 96.23 $\%$. Also, there is no significant improvement by using ultrafiltration with 1000 Dalton after using microfiltration (Figure 5) because the retentate was $95 \%$ of the total volume of the sample which is not economically feasible. By using a dose of $0.4 \mathrm{mg} / \mathrm{L}$ of the retentate, the residual turbidity was 2.29 NTU which is not much different from the result obtained from microfiltered sample through a $0.45 \mu \mathrm{m}$ membrane. On the other hand, the use of permeate, gives residual turbidity of 2.38 NTU by using a double dose which is $0.8 \mathrm{mg} / \mathrm{L}$ (Figure 6) compared to the retentate dosage. This means that the bioactive compounds were passing to the permeate. Furthermore, for the ultrafiltration, it was observed that the bioactive constituents were covering all the molecular weights presented in the sample, because $5 \%$ of permeate of ultrafiltration gave good coagulation activity only by using the double dose $(0.8 \mathrm{mg} / \mathrm{L}$ gave 93.20 removal efficiency and $0.4 \mathrm{mg} / \mathrm{L}$ of retentate gave $93.46 \%$ removal efficiency). The result indicated that there was no improvement in the product quality using 1000 Dalton ultrafiltration membrane.

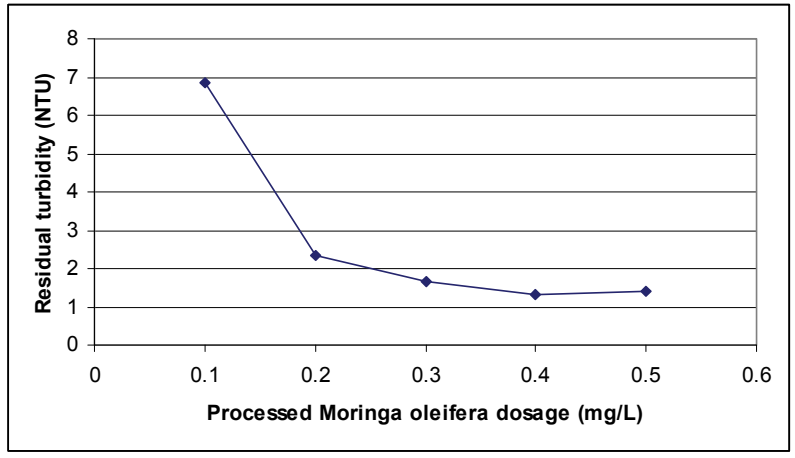

Figure 4. Residual Turbidity for microfiltration with $0.45 \mu \mathrm{m}$.

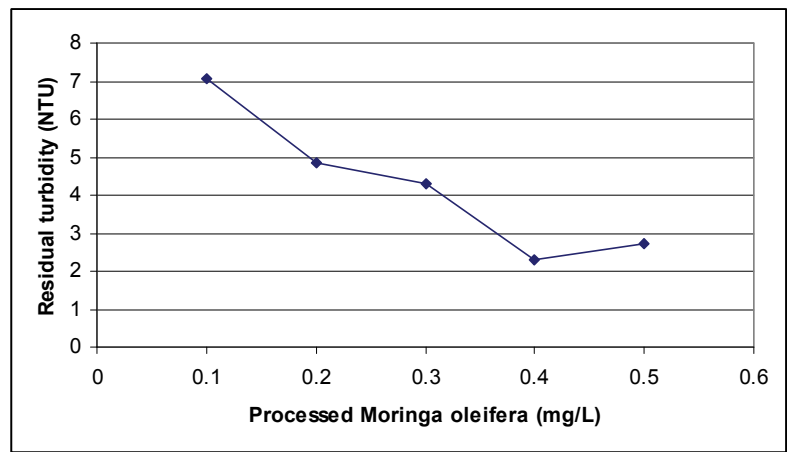

Figure 5. Residual Turbidity for microfiltration with $\mathbf{0 . 4 5}$ $\mu \mathrm{m}$ followed by 1000 Dalton (Retentate).

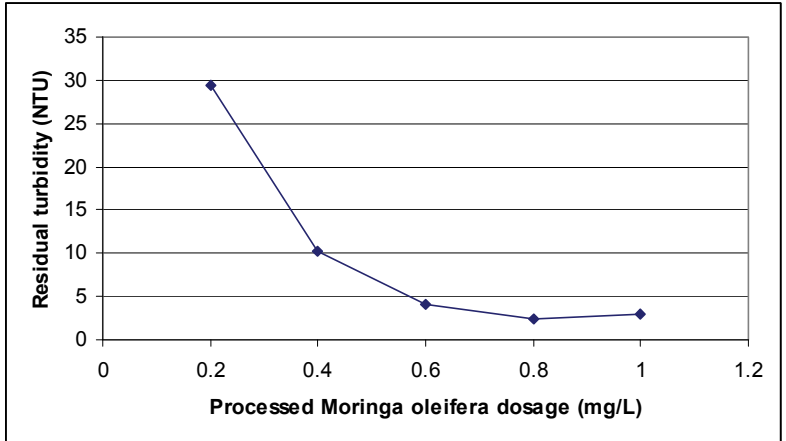

Figure 6. Residual Turbidity for microfiltration with 0.45 $\mu \mathrm{m}$ followed by 1000 Dalton (Permeate).

The ultrafiltration method involved the use of 1000 Dalton due to low molecular weight of less than 6500 Dalton (salt extraction method), in contrast with Ndabigengesere et al. [4] where the molecular weight was 13000 Dalton (water extraction method). The latter discovered out that the active components were retained on the 10000 Dalton membrane, while passed through the 30000 Dalton membrane.

\section{Conclusions}

The results showed that the cross flow filtration with microfiltration was sufficient to produce the natural coagulant with a more efficient and cost effective technique. It was observed that microfiltration with filter size of $0.45 \mu \mathrm{m}$ is enough to produce a natural coagulant with good coagulation activity. It was clear in this study that to include ultrafiltration step in the production process was considered as a loss, besides the waste of time and labour. The ultrafiltration was not beneficial because permeate was very low, and separation was inadequate to improve the coagulation activity.

\section{Acknowledgements}

The authors are grateful to the Ministry of Science Technology and Innovation of Malaysia for funding the Project (IRPA 09-02-08-10002 EAR).

\section{References}

[1] G. L. McConnachie, G. K. Folkard, M. A. Mtawali, and J. P. Sutherland, "Field trials of appropriate hydraulic flocculation processes," Water Research, Vol. 33, No. 6, pp. 1425-1434, 1999.

[2] http://www.who.int/water_sanitation_health/dwq/infectdi s/en/index.html.Retrieved October 24, 2008.

[3] http://www.epa.gov/safewater/contaminants/index.html.R etrieved October 24, 2008. 
[4] A. Ndabigengesere, K. S. Narasiah, and B. G. Talbot, "Active agents and mechanism of coagulant of turbid waters using Moringa oleifera," Water Research, Vol. 29, No. 2, pp. 703-710, 1995.

[5] S. A. Muyibi, S. A. Abbas, M. J. M. M. Noor, F. R. Ahmadon, "Enhanced coagulation efficiency of Moringa oleifera seeds through selective oil extraction," IIUM Engineering Journal, Vol. 4, No. 1, pp. 1-11, 2003.

[6] S. A. Muyibi and L. M. Evison, "Optimizing physical parameters affecting coagulation of turbid water with Moringa oleifera seeds," Water Research, Vol. 29, No. 12, pp. 2689-2695, 1995.

[7] T. Okuda, A. U. Baes, W. Nishijima, and M. Okada, "Improvement of extraction method of coagulation active components from Moringa oleifera seed," Water Research, Vol. 33, pp. 3373-3378, 1999.

[8] A. Ndabigengesere and K. S. Narasiah, "Quality of water treated by coagulation using Moringa oleifera seeds," Water Research, Vol. 32, No. 3, pp. 781-791, 1998.

[9] T. Okuda, A. U. Baes, W. Nishijima, and M. Okada, "Coagulation mechanism of salt solution extracted active component in Moringa oleifera seeds," Water Research, Vol. 35, No. 3, pp. 830-834, 2001.

[10] M. Broin, C. Santaella, S. Cuine, K. Kokou, G. Peltier, and T. Joët, "Flocculant activity of a recombinant protein from Moringa oleifera Lam Seeds," Applied Microbiol Biotechnol, Vol. 60, pp. 114-119, 2002.

[11] S. A. A. Jahn, "Using Moringa oleifera seeds as coagulant in developing countries," J. Am. Wat. Wks Ass., Vol. 6, pp. 43-50, 1988.

[12] S. A. Muyibi, M. J. M. M. Noor, T. K. Leong, and L. H. Loon, "Effect of oil extraction from Moringa oleifera seeds on coagulation of turbid water," Environment Studies, Vol. 59, No. 2, pp. 243-254, 2002. 
Appendix A

WANGSA MAJU WATER TREATMENT PLANT

\section{PROCESS FLOWCHART}

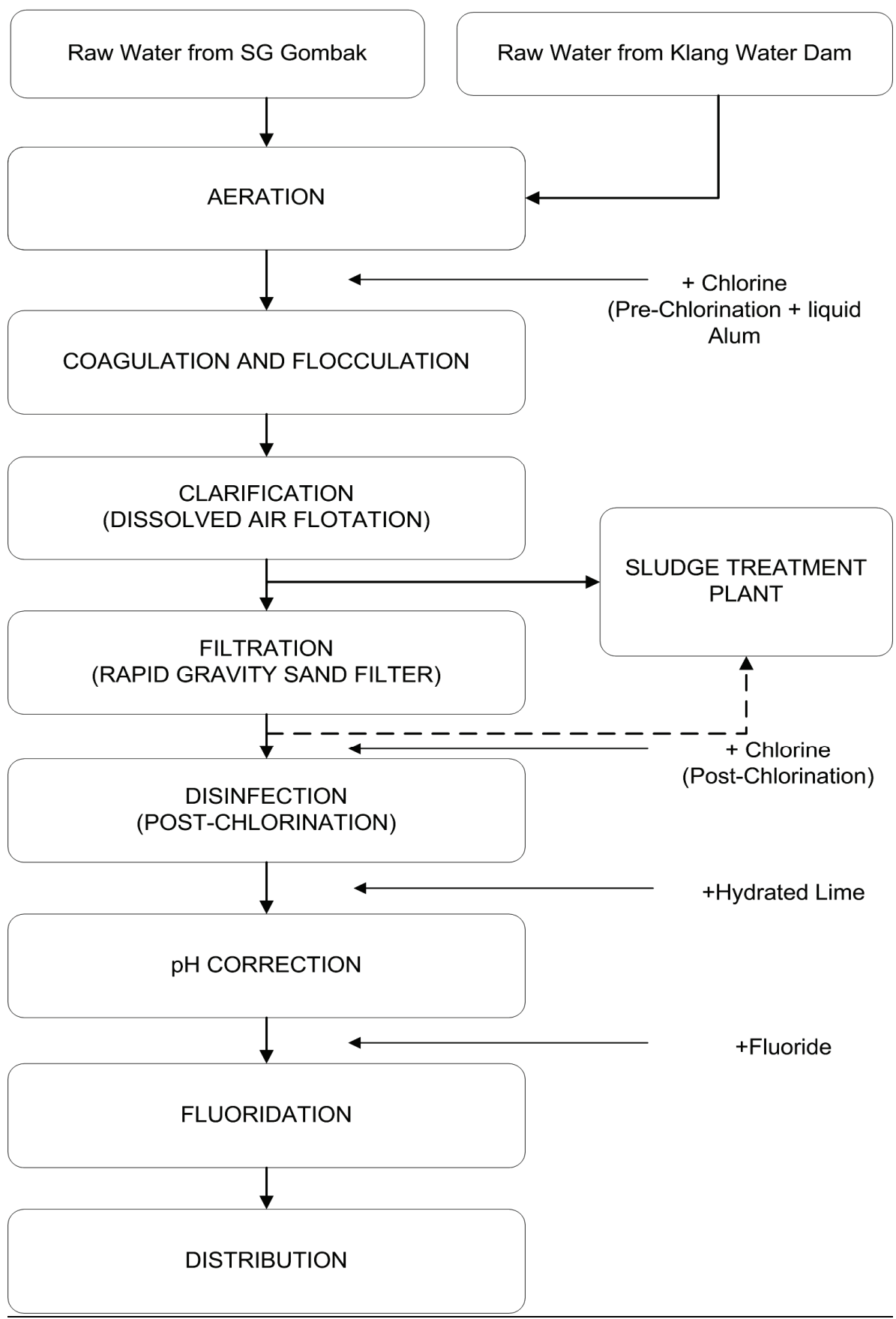

